\title{
Impact of multidisciplinary tumor boards on patients with rectal cancer (Review)
}

\author{
ARGYRIOS IOANNIDIS ${ }^{1}$, MICHAEL KONSTANTINIDIS ${ }^{2}$, SOTIRIOS APOSTOLAKIS ${ }^{3}$, \\ CHRISTOS KOUTSERIMPAS $^{4}$, NIKOLAOS MACHAIRAS ${ }^{5}$ and KONSTANTINOS M. KONSTANTINIDIS ${ }^{1}$ \\ ${ }^{1}$ Department of General, Laparoscopic, Robotic and Bariatric Surgery, Athens Medical Center, 15125 Athens; \\ ${ }^{2}$ National and Kapodistrian University of Athens, School of Medicine, 11527 Athens; \\ ${ }^{3}$ Department of Neurosurgery, KAT General Hospital of Attica, 14561 Athens; ${ }^{4}$ Department of Orthopaedics \\ and Traumatology, '251' Hellenic Air Force General Hospital, 11525 Athens; ${ }^{5}$ rd Department of Surgery, \\ University Hospital Attikon, National and Kapodistrian University of Athens, 12462 Athens, Greece
}

Received May 7, 2018; Accepted June 15, 2018

DOI: $10.3892 / \mathrm{mco} .2018 .1658$

\begin{abstract}
Oncological outcomes in patients with primary rectal cancer have markedly improved over the last few years, mainly due to the widespread application of the total mesorectal excision technique. This improvement should also be largely attributed to multiple specialties, other than colorectal surgery, such as radiology, oncology and pathology. Therefore, a multimodal approach is key to efficient and appropriate rectal cancer management. Multidisciplinary tumor (MDT) boards have become an important asset for the management and treatment of patients with rectal cancer, and a number of studies published to date suggest the beneficial effect of the multidisciplinary approach on the management of such patients. The available evidence demonstrates a modification of the treatment plan, attributed to the MDT implementation, in a non-negligible proportion of these patients. However, more studies are required in order to assess the exact impact of MDT boards on disease-free and overall survival of patients with primary rectal cancer.
\end{abstract}

\section{Contents}

1. Introduction

2. Discussion

3. Conclusion

Correspondence to: Dr Argyrios Ioannidis, Department of General, Laparoscopic, Robotic and Bariatric Surgery, Athens Medical Center, Distomou 5-7, 15125 Athens, Greece

E-mail: agis.ioannidis@gmail.com

Key words: multidisciplinary tumor board, multidisciplinary tumor conference, multidisciplinary tumor meeting, rectal cancer

\section{Introduction}

Oncological outcomes in patients with primary rectal cancer have markedly improved over the last few years, mainly due to the widespread application of the total mesorectal excision (TME) technique. This advancement should also be largely attributed to multiple specialties, other than colorectal surgery, such as radiology, oncology and pathology. Therefore, multimodality is key to delivering efficient and appropriate care to patients with rectal cancer (1).

Since the introduction of specific guidelines regarding the framework of the board (2) and the publication of the first diagnostic and treatment algorithm for multidisciplinary teams treating patients with colorectal cancer (3), multidisciplinary tumor (MDT) boards have become an important asset for the management and treatment of these patients, leading to significant improvement in the quality of medical services offered and, possibly, to higher survival rates $(4,5)$.

Taking these facts into consideration, presenting and discussing cases with primary rectal cancer at MDT meetings has become a requirement of the recently founded National Accreditation Program for Rectal Cancer, which is administered by the Commission on Cancer (6). A number of studies published to date suggest the beneficial effect of the multidisciplinary approach on the management of rectal cancer patients.

\section{Discussion}

MacDermid et al reported a statistically significant increase in the 3-year survival of patients with Dukes' stage C colorectal cancer who had undergone MDT evaluation compared with those who had not, while no statistically significant difference was identified with the survival rates of patients with Dukes' stage B disease (4). In addition, Richardson et al reported a considerable improvement in the TME specimen quality associated with MDT implementation (5).

Following the introduction of MDT boards, re-interpretation of preoperative magnetic resonance imaging (MRI) scans and tumor-related factors led to a different treatment plan in $29 \%$ of patients with primary rectal cancer, as reported by 
Snelgrove et al (7). Specifically, of the 36 patients included in that study, 28 (77\%) underwent complete to near-complete TME. Moreover, Fernando et al reported post-MDT clinical restaging in $\sim 7 \%$ (17/234) of their patients with rectal cancer (8).

Based on the results of their retrospective study of 687 cases of rectal cancer, Wu et al concluded that $\leq 25 \%$ of patients with recurrent rectal malignant tumors were able to receive curative treatment through the implementation of the MDT approach (9). Furthermore, the results of the application of the multidisciplinary approach in patients with metastatic rectal cancer, with 76 and 17\% achieving 3-year overall and progression-free survival, respectively, are encouraging (10). Interestingly, Lan et al reported that, after the establishment of the MDT conference, patients with lung and liver metastasis demonstrated a statistically significant increase in 3-year survival (11). It should be noted, however, that these results refer to the sum of colorectal cancer cases treated at the respective medical center, rather than rectal malignancies alone (11).

In 2014, Vaughan-Shaw et al (12), retrospectively compared 19 patients with pT1 rectal cancer treated in 2006 with 24 patients with pT1 rectal cancer treated in 2011. During 2011, all cases were discussed in a specialized early cancer MDT conference. In 2011, more patients underwent appropriate preoperative imaging compared with 2006 (MRI 18 vs. 12, transrectal ultrasound 20 vs. 4 and computed tomography 22 vs. 15 , respectively). The authors concluded that an improvement in the accuracy of preoperative staging of early rectal cancer, a reduction in margin positivity after local excision and an increase in the use of local excision were observed following the implementation of a specialized MDT conference (12).

In 2018, Karagkounis et al evaluated 408 rectal cancer cases discussed in MDT meetings (1). All presenting surgeons were required to report any changes to their treatment plan as a result of the conference. Modifications in the management or recommendations of additional evaluation were reported in 112 patients. The authors concluded that MDT boards changed the clinical management for a notable proportion of rectal cancer cases, independent of the attending surgeon's experience (1).

However, a recent systematic review suggested a rather insignificant effect of MDT boards on the improvement of overall survival. However, the primary tumor site was not taken into consideration (13). This, in conjunction with their limited feasibility, being restricted only to large referral centers, and the time commitment required for the realization of these meetings, have led to some skepticism over the necessity of MDT meetings in the preoperative and postoperative management of cancer patients (14). Yet, at the same time, accumulating evidence suggests that increased physician engagement in MDT boards is associated with earlier provision of treatment of rectal cancer (15).

\section{Conclusion}

In conclusion, there is a growing number of studies that support the positive impact of MDT conferences on the outcome of patients with primary rectal cancer. The available evidence demonstrates a change of the treatment plan, attributed to the MDT implementation, in a non-negligible proportion of these patients. However, more studies are required in order to assess the exact impact of MDT boards on disease-free and overall survival of patients with primary rectal cancer.

\section{Acknowledgements}

Not applicable.

\section{Funding}

No funding was received.

\section{Availability of data and materials}

Not applicable.

\section{Authors' contributions}

All authors meet the ICJME criteria for authorship, and they have read and approved the final version of this manuscript.

\section{Ethics approval and consent to participate}

Not applicable.

\section{Patient consent for publication}

Not applicable.

\section{Competing interests}

The authors declare that they have no competing interests to disclose.

\section{References}

1. Karagkounis G, Stocchi L, Lavery IC, Liska D, Gorgun E, Veniero J, Plesec T, Amarnath S, Khorana AA and Kalady MF: Multidisciplinary conference and clinical management of rectal Cancer. J Am Coll Surg 226: 874-880, 2018.

2. Ruhstaller T, Roe H, Thurlimann B and Nicoll JJ: The multidisciplinary meeting: An indispensable aid to communication between different specialities. Eur J Cancer 42: 2459-2462, 2006.

3. van de Velde CJ, Boelens PG, Borras JM, Coebergh JW, Cervantes A, Blomqvist L, Beets-Tan RG, van den Broek CB, Brown G, Van Cutsem E, et al: EURECCA colorectal: Multidisciplinary management: European consensus conference colon \& rectum. Eur J Cancer 50: 1.e1-1.e34, 2014.

4. MacDermid E, Hooton G, MacDonald M, McKay G, Grose D, Mohammed N, Porteous C: Improving patient survival with the colorectal cancer multi-disciplinary team. Colorectal Dis 11: 291-295 https://doi.org/10.1111/j.1463-1318.2008.01580.x.

5. Richardson B, Preskitt J, Lichliter W, Peschka S, Carmack S, de Prisco G and Fleshman J: The effect of multidisciplinary teams for rectal cancer on delivery of care and patient outcome: Has the use of multidisciplinary teams for rectal cancer affected the utilization of available resources, proportion of patients meeting the standard of care, and does this translate into changes in patient outcome? Am J Surg 211: 46-52, 2016.

6. Wexner SD and Berho ME: The rationale for and reality of the New National Accreditation Program for Rectal Cancer. Dis Colon Rectum 60: 595-602, 2017.

7. Snelgrove RC, Subendran J, Jhaveri K, Thipphavong S, Cummings B, Brierley J, Kirsch R and Kennedy ED: Effect of multidisciplinary cancer conference on treatment plan for patients with primary rectal cancer. Dis Colon Rectum 58: 653-658, 2015.

8. Fernando C, Frizelle F, Wakeman C, Frampton C and Robinson B: Colorectal multidisciplinary meeting audit to determine patient benefit. ANZ J Surg 87: E173-E177, 2017. 
9. Wu AW, Cai Y,Li YH, Wang L, Li ZW, Sun YS and Ji JF: Pattern and management of recurrence of mid-low rectal cancer after neoadjuvant intensity-modulated radiotherapy: Single-center results of 687 Cases. Clin Colorectal Cancer 17: e307-e313, 2018.

10. Holliday EB, Hunt A, You YN, Chang GJ, Skibber JM, Rodriguez-Bigas MA, Bednarski BK, Eng C, Koay EJ, Minsky BD, et al: Short course radiation as a component of definitive multidisciplinary treatment for select patients with metastatic rectal adenocarcinoma. J Gastrointest Oncol 8: 990-997, 2017.

11. Lan YT, Jiang JK, Chang SC, Yang SH, Lin CC, Lin HH, Wang HS, Chen WS, Lin TC and Lin JK: Improved outcomes of colorectal cancer patients with liver metastases in the era of the multidisciplinary teams. Int J Colorectal Dis 31: 403-411, 2016.

12. Vaughan-Shaw PG, Wheeler JM and Borley NR: The impact of a dedicated multidisciplinary team on the management of early rectal cancer. Colorectal Dis 17: 704-709, 2015.
13. Pillay B, Wootten AC, Crowe H, Corcoran N, Tran B, Bowden P, Crowe $\mathrm{J}$ and Costello AJ: The impact of multidisciplinary team meetings on patient assessment, management and outcomes in oncology settings: A systematic review of the literature. Cancer Treat Rev 42: 56-72, 2016

14. Lowes M, Kleiss M, Lueck R, Detken S, Koenig A, Nietert M, Beissbarth T, Stanek K, Langer C, Ghadimi M, et al: The utilization of multidisciplinary tumor boards (MDT) in clinical routine: Results of a health care research study focusing on patients with metastasized colorectal cancer. Int J Colorectal Dis 32: 1463-1469, 2017.

15. Onukwugha E, Petrelli NJ, Castro KM, Gardner JF, Jayasekera J, Goloubeva O, Tan MT, McNamara EJ, Zaren HA and Asfeldt T: Impact of multidisciplinary care on processes of cancer care: A multi-institutional study. J Oncol Pract 12: 157-168, 2016. 